\title{
Gestão Ambiental Empresarial: um Levantamento da Produção Científica Brasileira Divulgada em Periódicos da Área de Administração entre 1996 e 2005
}

\section{Environmental Management in Companies: an Analysis of the Scientific Production on Environmental Management in Companies Published in the Main Journals on Administration between 1996 and 2005}

Charbel José Chiappetta Jabbour * Doutor em Engenharia de Produção pela EESC/USP. Professor do Depto. de Engenharia de Produção da Faculdade de Engenharia, UNESP/ Bauru, Bauru/SP, Brasil.

Fernando César Almada Santos Doutor em Administração de Empresas pela EAESP/FGV. Professor da EESC/USP, São Carlos/SP, Brasil.

José Carlos Barbieri Doutor em Administração de Empresas pela EAESP/FGV. Professor Adjunto da EAESP/FGV, São Paulo/SP, Brasil.

*Endereço: Faculdade de Engenharia - UNESP/Bauru, Av. Engenheiro Luiz E. C. Coube, s/n, Bauru/SP, 17033-360. E-mail: cjabbour@terra.com.br 


\section{RESUMO}

Nesta pesquisa, conduz-se uma meta-análise da produção científica em gestão ambiental empresarial, registrada em seis dos principais periódicos em administração no Brasil (RAE, RAEE, RAUSP, RAP, REAd e RAC), no período entre 1996 e 2005. Para tanto examina-se essa produção acadêmica com base nos seguintes parâmetros: aumento da produção; origem de autoria; perfil metodológico; conteúdo e abrangência das análises; e nível de internacionalização das referências bibliográficas. O diagnóstico que se infere é: a produção acadêmica em gestão ambiental empresarial corresponde a apenas 2,30\% da total em administração; parte significativa dessa produção recebe inspiração internacional, principalmente dos trabalhos de Hunt e Auster (1990) e de Porter e Linde (1995); e restringese a um pequeno grupo de pesquisadores e instituições, uma vez que quase $60 \%$ da produção observada é oriunda de apenas cinco instituições. Contribui-se, assim, com a sistematização da produção acadêmica na área de gestão ambiental empresarial e são fornecidos subsídios para esse campo de pesquisa no Brasil.

Palavras-chave: produção acadêmica; gestão ambiental empresarial; balanço da literatura.

\section{Abstract}

The aim of this article is to analyse the scientific production on environmental management in companies published in the six main journals on administration in Brazil (RAE, RAEE, RAUSP, RAP, REAd and RAC), during the period between 1996 and 2005. The following aspects were used in order to examine this academic production: quantitative progress of production; source of authorship; methodological profile; publication content and breadth; and internationalization level of references. The main concerns of this diagnosis are: the academic production on environmental management in companies corresponds to only $2,30 \%$ of the total production in administration; a significant part of this production is stimulated by international studies, mainly Hunt and Auster (1990) and Porter and Linde (1995); Brazilian research is restricted to small group of researchers and institutions, as almost $60 \%$ of the analyzed articles were published by only five institutions. Thus, this article contributes to the systematization of the academic production on environmental management in companies, as well as it provides insights for this field of research in Brazil.

Key words: academic production; environmental management in companies; analysis of literature. 


\section{INTRODUÇÃO}

A produção acadêmica em administração no Brasil passou por profundas transformações, dentre as quais se destaca seu significativo incremento quantitativo, principalmente durante a década de 1990. Tal crescimento foi fomentado pela expansão dos cursos de pós-graduação em administração e pelo exercício de maior pressão da Coordenadoria de Aperfeiçoamento do Ensino Superior [CAPES], no sentido de estimular a produção acadêmica e sua divulgação sistemática em periódicos de excelência e abrangência nacional.

O crescente vigor da produção científica em administração se reflete, outrossim, na quantidade dos veículos acadêmicos incumbidos pela divulgação dessas pesquisas. Nesse sentido, observa-se que o número de periódicos nacionais considerados fóruns acadêmicos que comportam produção acadêmica qualificada, isto é, classificados no sistema Qualis como de abrangência nacional nível A, dobrou em menos de uma década. Quer-se mencionar a adição dos periódicos Revista Eletrônica de Administração [REAd], Revista de Administração Contemporânea [RAC] e Revista de Administração de Empresas Eletrônica [RAEE], esta última criada há menos de dez anos, ao grupo de periódicos que até então dominava o cenário de divulgação da produção acadêmica qualificada em administração: a Revista de Administração de Empresas [RAE] a Revista de Administração Pública [RAP] e a Revista de Administração [RAUSP]. A forma de divulgação das pesquisas também passou por modificações, ocasionadas, principalmente, pelo desenvolvimento de tecnologias de comunicação e informação. Como corolário, tem-se que, atualmente, de forma parcial ou cabal, a REAd, a RAC, a RAEE e a RAE disponibilizam o conteúdo de suas edições em formato digital.

No bojo desse processo, diversas preocupações com a qualidade da produção acadêmica brasileira em administração tornaram-se explícitas, motivando a condução de (meta) estudos e balanços retrospectivos, desenvolvidos com maior frequiência após 1997 (Tonelli, Caldas, Lacombe, \& Tinoco, 2003). A despeito da proliferação desse tipo de pesquisa, não se identificaram estudos dedicados à análise da produção acadêmica em gestão ambiental empresarial, subárea do campo de administração que se tornou expressiva durante a década de 1990, tanto no Brasil quanto internacionalmente. De fato, a discussão de temas ambientais no contexto organizacional já se mostra como necessidade consolidada, mas os meandros inerentes à produção científica dessa área encontram-se pouco explorados. Como corolário dessa lacuna bibliográfica, o presente trabalho aborda a seguinte problemática de pesquisa: quais as principais características da produção acadêmica 
brasileira em gestão ambiental empresarial registrada em periódicos da área de administração entre 1996 e 2005 ?

Para lançar luzes sobre essa problemática, organizou-se o trabalho da seguinte maneira: (a) na segunda seção, é apresentada uma breve descrição dos balanços sobre a bibliografia administrativa de diversos campos de pesquisa; (b) na terceira seção, discorre-se sobre as características da produção acadêmica em gestão ambiental empresarial no Brasil; (c) os aspectos metodológicos são delineados na quarta seção; (d) os resultados são apresentados na quinta seção; e (e) as considerações finais são levadas a cabo na sexta seção deste trabalho.

\section{Breve Revisão dos Balanços da Produção Acadêmica em AdMINISTRAÇÃo NO Brasil}

A realização de balanços sobre a produção científica é usual em termos mundiais. Tais estudos ocupam lugar de destaque em diversos periódicos internacionais, principalmente naqueles dedicados à divulgação da produção científica em ciências exatas, como apresentam Huber e Wagner-Dobler (2001a, 2001b). Também são comuns na análise da produção acadêmica das ciências biológicas e na área de ciências humanas, abordando as subáreas de economia e administração.

Foi na década de 1990 que a publicação de balanços da produção acadêmica em administração começou a ganhar maior destaque no Brasil. No início, o principal fórum de divulgação desses balanços foi o Encontro Nacional da Associação Nacional de Pós-graduação e Pesquisa em Administração [ENANPAD]. Em seu início, os balanços da produção acadêmica brasileira não recebiam destaque em periódicos considerados pela CAPES como de excelência. Atribui-se o pioneirismo da aplicação desse tipo de estudo às pesquisas de Siqueira (1988) e Machado-daSilva, Cunha e Amboni (1990), que realizaram uma análise da produção científica nacional concernente ao tema Organizações.

Vários outros balanços foram realizados, explorando diversas subáreas da administração. Gosling e Gonçalves (2004) analisaram os procedimentos metodológicos de autores de artigos em estratégia, publicados no ENANPAD, entre os anos de 1997 e 2002. Segundo os autores, a análise possibilita a identificação do método qualitativo de pesquisa predominante, além de melhoria significativa da qualidade dos artigos analisados. Iizuka e Sano (2004) analisaram a produção científica sobre o Terceiro Setor publicada nos anais do ENANPAD no período de 1997 a 2002. Nessa avaliação, identificaram os principais autores da área, as referências mais utilizadas, metodologias empregadas e as lacunas teóricas e práticas a serem exploradas. 
Paiva e Cordeiro (2002) investigaram a evolução da produção científica em empreendedorismo publicada nos anais do ENANPAD de 1998 a 2001. Concluem que o tema mais explorado é a ligação entre estratégia e empreendedorismo nos níveis individual e empresarial. O cunho metodológico é predominantemente exploratório e as temáticas, ainda são desenvolvidas de forma embrionária.

A área de recursos humanos é analisada de forma recorrente, despontando como tema administrativo que possui maior quantidade de balanços acadêmicos realizados (Caldas \& Tinoco, 2004; Caldas, Tinoco, \& Chu, 2003; Roesch, Antunes, \& Silva, 1997; Tonelli et al., 2003). De forma pioneira, Siqueira (1988) examinou os artigos publicados na área de recursos humanos entre 1982 e 1987, concluindo que a FEAUSP foi a instituição com maior número de trabalhos publicados e que, de forma agregada, a tendência observada é de crescimento quantitativo constante do número de artigos publicados. Tonelli et al. (2003) exploraram mais de 400 artigos publicados, em periódicos e anais de eventos, constatando que, a despeito de a produção acadêmica da área ter aumentado na última década,

seu escopo temático é contestado pelo constante crescimento e autonomia do campo de comportamento organizacional; sua base epistemológica é eminentemente funcionalista; a base metodológica é frágil, predominando estudos de caso tipicamente ilustrativos da teoria consolidada; e a diversidade de origem é baixa: mais de $65 \%$ da produção vem apenas de 7 programas de pós-graduação (p. 105).

Ainda nesse escopo analítico, podem ser citados os trabalhos de Roesch et al. (1997), que analisaram dissertações de mestrado produzidas na área de recursos humanos e organizações. Estes autores, após a análise de 74 trabalhos, concluem que, enquanto a área de recursos humanos apresenta uma tendência de adoção dos métodos quantitativos de pesquisa, predomina, na área de organizações, a adoção de estudo de casos como estratégia de pesquisa.

Outro exemplo de meta-estudo em recursos humanos é o conduzido por Caldas et al. (2003), cujos resultados indicam que a produção possui alto índice de autocitação dos autores; e que a USP, UFMG, UFRGS e a FGV-EAESP são as instituições mais citadas na área. Em pesquisa similar, Caldas e Tinoco (2004) afirmam que a produção acadêmica em recursos humanos desenvolve-se à luz de inspiração intelectual estrangeira, além de ser elaborada por um conjunto limitado de autores e programas de pós-graduação.

No campo de pesquisa em Sistemas de Informação, a condução de balanços da produção acadêmica também se mostra presente. Em recente estudo, Lunardi, Rios e Maçada (2005) afirmam que há concentração da referida produção em alguns poucos programas de pós-graduação em administração, principalmente nos precursores da área de sistemas de informação. Hoppen (1998) analisou 163 artigos da área de 
sistemas de informação publicados em revistas de administração, constatando que "as pesquisas qualitativas e as surveys são as metodologias utilizadas em $72 \%$ das pesquisas empíricas e que a qualidade científica dos artigos é baixa" (p. 151). Posteriormente, Meirelles e Hoppen (2005), ao analisarem 343 artigos publicados nos principais periódicos de administração, afirmam que a produção científica em sistemas de informação demonstra uma característica de significativa redução na proporção de ensaios teóricos, havendo um predomínio do tema de Administração da Informação.

A produção acadêmica da subárea Finanças foi, por vezes, alvo de meta-estudos. Destaca-se, nesse contexto, o balanço efetuado por Leal, Oliveira e Soluri (2003), que sistematizaram uma amostra composta por 551 artigos da área de finanças publicados entre 1974 e 2001, em diversos periódicos das áreas de administração e economia. Após uma profunda análise, os autores asseveraram que a produção acadêmica em finanças se concentra em poucos autores nacionais, sendo o Rio de Janeiro o Estado que comporta autores com maior produção científica nesse campo.

Outra subárea freqüentemente abordada por balanços da produção acadêmica é a de Marketing, como fizeram Botelho e Macera (2001), ao analisarem teses e dissertações desse campo de investigação produzidas por discentes da FGV-EAESP. Vieira (2003), ao observar 272 artigos publicados nos principais periódicos brasileiros em administração, constatou que, a despeito do campo de pesquisa em marketing no Brasil se encontrar em expansão, a produção científica produzida nacionalmente tende a não ser contemplada nos trabalhos desenvolvidos no âmbito da área.

Como se percebe, a quantidade de meta-estudos administrativos tende a se expandir, contemplando diversas subáreas da administração. No bojo desse processo, surgem estudos sobre a produção científica em contabilidade (Mendonça, Riccio, Cardoso, \& Sakata, 2005), em empreendedorismo (Paiva \& Cordeiro, 2002) e no campo de pesquisa sobre estratégia organizacional (Gosling \& Gonçalvez, 2004), para citar apenas alguns. Mas, apesar da evidente tendência de especificidade dos meta-estudos indicados, não foram encontrados, na literatura especializada, balanços sobre a produção acadêmica em gestão ambiental empresarial, subárea da administração que vem ganhando notoriedade. Com efeito, pouco há de sistematização sobre a produção científica dessa área de pesquisa e, por isso, a próxima seção trata de sua gênese e expansão no Brasil.

\section{Produção Acadêmica Brasileira em Gestão Ambiental EMPRESARIAL}

A produção acadêmica brasileira em gestão ambiental empresarial encontrou na 
década de 1990 o marco de sua gênese e expansão. Acompanhou, assim, o incremento da produção científica internacional, que ocorreu com as publicações de trabalhos clássicos na área, tais como o de Buchoolz (1998), Hunt e Auster (1990) e Hart (1995).

No Brasil, o tema começou a ganhar destaque com a publicação de algumas obras pioneiras. Donaire (1994) realizou um estudo sobre a interiorização da dimensão ambiental na organização de empresas industriais. Maimon (1996) abordou questões concernentes à relação entre exportação e adoção de instrumentos de gestão ambiental em empresas brasileiras. As sínteses dessas obras foram publicadas em periódicos nacionais (Donaire, 1994; Maimon, 1994).

Nesse período, a RAE se tornou um importante fórum para o debate da gestão ambiental e sua relação com as firmas. Na esteira desse processo, foram publicados os trabalhos de Neder (1992), Mazon (1992), M. T. S. Souza (1993), Carneiro, Magyar e Granja (1993), Cicco (1994), Guimarães, Demajorovic e Oliveira (1995) e Nahuz (1995). Ressalte-se que esses trabalhos mantinham relação estreita com a temática da gestão ambiental no contexto empresarial. Com efeito, em período relativamente curto, a RAE comportou a quase totalidade da produção acadêmica em gestão ambiental no início da década de 1990, período em que o tema se consolidou nos fóruns internacionais e ganhou projeção no contexto nacional. Vale ressaltar que nesse mesmo período organizaram-se as primeiras versões do Encontro Nacional de Gestão Empresarial e Meio Ambiente [ENGEMA], evento bianual dedicado a incentivar a produção científica em gestão ambiental empresarial.

No período entre 1996-2005, a produção acadêmica sobre esse campo de pesquisa tornou-se mais difusa e, em que pesem as diferenças quantitativas, com representações nos mais importantes periódicos nacionais de administração. No que tange à produção acadêmica em gestão ambiental empresarial registrada nos anais de eventos, a perspectiva é de incremento. Mais especificamente, no caso do ENANPAD, a área que compreende os trabalhos em gestão ambiental, denominada atualmente como Administração Pública e Gestão Social - Gestão Social e Meio Ambiente [APS-C], foi a segunda com maior número de submissões de artigos candidatos à publicação vis-à-vis as demais áreas, passando de 194 artigos submetidos em 2005 para 215 trabalhos submetidos em 2006. Por seu turno, o ENGEMA também vem apresentando números crescentes de trabalhos submetidos; em 2005 foram aprovados cerca de 250 artigos para apresentação. A despeito da importância crescente da pesquisa em gestão ambiental, ainda não foram encontrados, até a presente data, balanços sobre a produção científica dessa área. Assim, justifica-se a condução desta pesquisa, cujos procedimentos metodológicos são descritos a seguir. 


\section{Procedimentos Metodológicos}

A produção acadêmica em gestão ambiental empresarial abordada neste trabalho constitui-se de pesquisas publicadas em seis periódicos nacionais dedicados à divulgação de estudos em administração no período de 1996 a 2005, sendo eles:

. Revista Eletrônica de Administração [REAd];

. Revista de Administração de Empresas - Eletrônica [RAEE];

. Revista de Administração Contemporânea [RAC];

. Revista de Administração Pública [RAP];

. Revista de Administração de Empresas [RAE]; e

. Revista de Administração [RAUSP].

A escolha dos periódicos RAE, RAC, RAP e RAUSP se justifica na medida em que diversos estudos e balanços científicos se basearam na produção acadêmica dessas revistas, a exemplo de Tonelli et al. (2003). Tais periódicos também compõem a amostra analisada por Hoppen (1998). Arkader (2003) considerou as revistas RAE, RAUSP e RAC como os periódicos nacionais mais expressivos da área de administração. Vieira (2003) analisou a RAE e a RAUSP, por considerá-las os periódicos em administração mais tradicionais. Em análise sobre a produção acadêmica da área de finanças no Brasil, Leal et al. (2003) compuseram o grupo de periódicos investigados com diversas revistas das áreas de economia e de administração; desta última, destacaram-se a RAE, a RAC e a RAUSP, as quais compõem a base de análise de meta-estudos mais recentes (Meirelles \& Hoppen, 2005; Mendonça et al., 2005).

Já a opção por investigar as revistas REAd e RAEE se justifica porque tais periódicos atingiram o reconhecimento máximo da CAPES para fóruns acadêmicos em administração. Não obstante, tais periódicos são representativos das transformações que se desenrolam no âmbito da divulgação da produção científica nacional: suas edições são disponibilizadas integralmente de forma digital, não possuindo difusão impressa. Dessa forma, pode-se indicar que a REAd e a RAEE se encontram consolidadas como veículos de excelência da produção acadêmica em administração.

Esta pesquisa não analisou as publicações em gestão ambiental empresarial registradas nos anais dos Encontros Nacionais da Associação Nacional de Pósgraduação e Pesquisa em Administração [ENANPAD] por dois motivos: (a) objetiva comparar a produção científica qualificada em administração que, segundo critérios 
da CAPES, exclui a produção acadêmica veiculada em anais de congressos e eventos, incluindo a do ENANPAD, por não serem considerados periódicos de excelência, com amplitude de difusão nacional; e (b) segundo Tonelli et al. (2003) "os critérios de aprovação para publicação nos periódicos são mais seletivos e rigorosos do que os do ENANPAD” (p. 110).

Temporalmente, esta pesquisa discorre sobre a produção científica em gestão ambiental empresarial em uma década (1996-2005). Esse período de investigação foi considerado ideal por alguns trabalhos, como o de Tonelli et al. (2003). No que concerne ao método de análise dos trabalhos, esta pesquisa se inspira naqueles empregados nos principais balanços e meta-estudos presentes na bibliografia especializada em administração (Arkader, 2003; Bignetti \& Paiva, 1997; Botelho \& Macera, 2001; Caldas \& Tinoco, 2004; Gosling \& Gonçalves, 2004; Hoppen, 1998; Leal et al., 2003; Meirelles \& Hoppen, 2005; Mendonça et al., 2005; Roesch et al., 1997; Tonelli et al., 2003; Vieira, 2003).

Por sua natureza multi, inter e transdisciplinar (Barbieri, 2004), a literatura em gestão ambiental analisada neste trabalho mantém vínculos, diretos ou indiretos, com o âmbito empresarial, de forma que foram excluídas da análise as pesquisas que abordaram temas de gestão ambiental desconectados da dinâmica organizacional ou que não evidenciaram implicações claras de suas proposições para as organizações. Dessa forma, foram selecionadas para análise pesquisas que tratam do

processo adaptativo e dinâmico, por meio do qual as organizações definem e redefinem suas expectativas e metas relacionadas à proteção do ambiente, selecionando estratégias e meios para atingir esses objetivos num tempo determinado, por meio de constante avaliação de sua interação com o meio ambiente externo (Seiffert, 2005, p. 24).

Cinco variáveis são contempladas como perspectiva analítica: (a) número de trabalhos publicados em gestão ambiental empresarial em relação ao total da produção acadêmica em administração no período; (b) conteúdo dos trabalhos e sua abrangência analítica; (c) perfil metodológico; (d) demografia de autoria; e (e) origem das referências bibliográficas utilizadas.

\section{Resultados}

Nesta seção, são apresentados os principais resultados do meta-estudo sobre a produção científica em gestão ambiental divulgada nos principais fóruns acadêmicos da área de administração. A exposição dos resultados segue as variáveis analíticas declaradas na seção de procedimentos metodológicos. 


\section{A Produção em Gestão Ambiental Vis-à-vis à Produção Total}

Pode-se afirmar que a produção científica qualificada em administração quase dobrou ao longo do período de referência. Com base nos dados quantitativos apurados nas datas extremas do período analisado (1996 e 2005), temos que a produção acadêmica em administração passou de 117 artigos publicados para 233. Ora, esse significativo aumento da quantidade de artigos publicados reflete a própria expansão do número de periódicos disponíveis. Com efeito, a expansão da produção científica em administração só foi possível com a gênese e consolidação de revistas como a RAC, em 1997, e a RAE-Eletrônica, em 2002.

A hipótese de que a expansão da quantidade de periódicos disponíveis foi determinante do incremento quantitativo da produção acadêmica em administração é validada pela análise do caso da RAUSP, por exemplo. Percebe-se que na RAUSP foram publicados 31 artigos no ano de 1996 e 25 artigos em 2005. A pouca variação nas quantidades publicadas em uma década pode também ser observada nos casos da RAE e da RAP. Assim, constata-se que a edição de novas revistas foi fundamental para o incremento quantitativo da produção acadêmica em administração no Brasil, e a conseqüente difusão da produção científica nacional.

Em uma década (de 1996 a 2005), foram publicados 1785 artigos pelos seis periódicos analisados, conforme indica a Tabela 1. Ainda nessa tabela, são ressaltadas as quantidades de artigos publicados em cada um dos periódicos considerados, tendo em vista quatro variáveis: (a) produção acadêmica anualmente registrada em cada revista; (b) produção acadêmica publicada no periódico na década; (c) produção acadêmica anual consolidada de todos os periódicos; e (d) produção acadêmica relativa de cada periódico.

Tabela 1: Produção Acadêmica em Administração entre 1996 e 2005

\begin{tabular}{ccccccccccccc}
\hline $\begin{array}{l}\text { REVISTA/ } \\
\text { PERÍODO }\end{array}$ & $\mathbf{1 9 9 6}$ & $\mathbf{1 9 9 7}$ & $\mathbf{1 9 9 8}$ & $\mathbf{1 9 9 9}$ & $\mathbf{2 0 0 0}$ & $\mathbf{2 0 0 1}$ & $\mathbf{2 0 0 2}$ & $\mathbf{2 0 0 3}$ & $\mathbf{2 0 0 4}$ & $\mathbf{2 0 0 5}$ & $\begin{array}{c}\text { Total } \\
\text { por } \\
\text { Revista }\end{array}$ & $\begin{array}{c}\text { Total } \\
\text { por } \\
\text { Revista } \\
(\boldsymbol{\%})\end{array}$ \\
\hline RAUSP & 31 & 32 & 29 & 27 & 36 & 32 & 28 & 26 & 29 & 28 & 298 & $16,69 \%$ \\
\hline RAC & 0 & 19 & 23 & 22 & 25 & 41 & 28 & 41 & 43 & 47 & 289 & $16,19 \%$ \\
\hline RAP & 48 & 47 & 56 & 44 & 52 & 42 & 33 & 48 & 50 & 42 & 462 & $25,88 \%$ \\
\hline RAE & 25 & 29 & 27 & 33 & 35 & 30 & 33 & 32 & 31 & 37 & 312 & $17,64 \%$ \\
\hline RAEE & 0 & 0 & 0 & 0 & 0 & 0 & 32 & 26 & 25 & 13 & 96 & $5,38 \%$ \\
\hline REAd & 13 & 15 & 5 & 24 & 29 & 35 & 34 & 47 & 60 & 60 & 322 & $18,04 \%$ \\
\hline \hline Total & 117 & 142 & 140 & 150 & 177 & 180 & 188 & 220 & 238 & 233 & 1785 & $100,00 \%$ \\
\hline
\end{tabular}

A produção acadêmica sobre gestão ambiental registrada nesses periódicos corresponde a apenas $2,30 \%$ do total de artigos publicados, mais precisamente a apenas 41 artigos sobre gestão ambiental empresarial, em uma amostra de 1.785 
pesquisas registradas. Conforme mostra a Tabela 2, em uma década, foram publicados quatro artigos em cada uma das revistas RAUSP, RAC e RAE; na RAP, foram publicados 12 artigos; na REAd, 15; e na RAE-Eletrônica, 2.

A REAd desponta como o periódico com maior número de publicações, tanto em termos absolutos como relativos, sendo a principal causa desse fato o lançamento de uma edição especial sobre o tema no ano de 2002, que resultou na divulgação de 8 artigos. A RAP aparece como o segundo periódico que mais publica artigos sobre gestão ambiental empresarial, sendo acompanhada, em termos percentuais, pela RAE-Eletrônica, RAC, RAUSP e RAE, respectivamente.

\section{Tabela 2: Produção Acadêmica em Gestão Ambiental Empresarial entre 1996 e 2005 por Revista, Tendo em vista o Total Verificado nesta Área}

\begin{tabular}{ccccccccccccc}
\hline $\begin{array}{l}\text { REVISTA/ } \\
\text { PERÍODO }\end{array}$ & $\mathbf{1 9 9 6}$ & $\mathbf{1 9 9 7}$ & $\mathbf{1 9 9 8}$ & $\mathbf{1 9 9 9}$ & $\mathbf{2 0 0 0}$ & $\mathbf{2 0 0 1}$ & $\mathbf{2 0 0 2}$ & $\mathbf{2 0 0 3}$ & $\mathbf{2 0 0 4}$ & $\mathbf{2 0 0 5}$ & $\begin{array}{c}\text { Total } \\
\text { por } \\
\text { Revista }\end{array} \begin{array}{c}\text { Total } \\
\text { por } \\
\text { Revista } \\
(\boldsymbol{\%})\end{array}$ \\
\hline RAUSP & 0 & 1 & 0 & 0 & 0 & 0 & 0 & 1 & 1 & 1 & 4 & $9,76 \%$ \\
\hline RAC & 0 & 0 & 1 & 1 & 0 & 0 & 1 & 0 & 1 & 0 & 4 & $9,76 \%$ \\
\hline RAP & 1 & 3 & 0 & 1 & 1 & 1 & 1 & 2 & 1 & 1 & 12 & $29,27 \%$ \\
\hline RAE & 0 & 1 & 0 & 0 & 3 & 0 & 0 & 0 & 0 & 0 & 4 & $9,76 \%$ \\
\hline RAEE & 0 & 0 & 0 & 0 & 0 & 0 & 0 & 2 & 0 & 0 & 2 & $4,88 \%$ \\
\hline REAd & 0 & 0 & 0 & 0 & 1 & 1 & 8 & 2 & 1 & 2 & 15 & $36,57 \%$ \\
\hline \hline Total & 2 & 4 & 1 & 2 & 5 & 2 & 10 & 7 & 4 & 4 & 41 & $100,00 \%$ \\
\hline
\end{tabular}

Durante a década de 1996 a 2005, o ano de 2002 aparece como aquele em que mais foram publicados artigos sobre gestão ambiental empresarial, constatação que também pode ser atribuída à publicação da edição especial realizada pela REAd. Não fosse a expressiva atuação da REAd, a produção acadêmica observada no ano de 2002 não superaria a média de suas congêneres.

\section{Perfil Metodológico da Produção, Conteúdo e Abrangência Analítica, Demografia de Autoria e Referências Utilizadas}

Esta seção apresenta as principais contribuições das pesquisas investigativas para o campo da gestão ambiental empresarial, categorizando-as segundo o perfil metodológico (Tabelas 1, 2, 3, 4, 5 e 6). Esta pesquisa sistematiza cada um dos artigos analisados, pois se acredita que esse breve relato pode ser de grande utilidade aos pesquisadores em gestão e dirigentes organizacionais. A classificação metodológica segue o referencial proposto por Machado-da-Silva et al. (1990), que foi referendado por diversos balanços acadêmicos, tal como o empreendido por Tonelli et al. (2003). Assim, os trabalhos foram classificados em: 
- Pesquisa empírica: quando o trabalho se concentra na observação e análise de dados, sem apresentar fundamentação teórica prévia.

- Pesquisa teórico-empírica: quando o estudo apresenta dados coletados, que são então analisados e confrontados com correntes teóricas revisadas.

. Pesquisa teórica: são trabalhos que, por não apresentarem dados empíricos, se limitam à articulação, formulação e contraposição de conceitos teóricos.

\section{Tabela 3: Contribuição e Categorização Metodológica das Pesquisas Publicadas na RAE entre 1996 e 2005}

\begin{tabular}{lll}
\hline \multicolumn{1}{c}{ Pesquisa } & \multicolumn{1}{c}{ Contribuição para o campo de investigação } & \multicolumn{1}{c}{$\begin{array}{c}\text { Perfil } \\
\text { metodológico }\end{array}$} \\
\hline C. S. Sanches (1997) & $\begin{array}{l}\text { Discorre sobre as formas de interiorização dos custos ambientais nas } \\
\text { empresas }\end{array}$ & Teórico \\
\hline Layrargues (2000) & $\begin{array}{l}\text { Contesta a eficácia da ISO 14001 e da adoção de tecnologias } \\
\text { ambientalmente adequadas como promotoras do posicionamento empresarial } \\
\text { ante a dimensão ambiental }\end{array}$ & Teórico \\
\hline Mello (2000) & $\begin{array}{l}\text { Mostra a viabilidade financeira de sistemas sustentáveis de produção de } \\
\text { cana-de-açúcar do interior paulista }\end{array}$ & Teórico-Empírico \\
\hline C. S. Sanches (2000) & $\begin{array}{l}\text { Evidencia as principais característica da gestão ambiental proativa, } \\
\text { discorrendo sobre os potenciais ganhos empresariais decorrentes dessa } \\
\text { postura }\end{array}$ & Teórico \\
\hline
\end{tabular}

\section{Tabela 4: Contribuição e Categorização Metodológica das Pesquisas Publicadas na RAEE entre 1996 e 2005}

\begin{tabular}{llc}
\hline \multicolumn{1}{c}{ Pesquisa } & \multicolumn{1}{c}{ Contribuição para o campo de investigação } & $\begin{array}{c}\text { Perfil } \\
\text { metodológico }\end{array}$ \\
\hline Corazza (2003) & $\begin{array}{l}\text { Caracteriza duas formas de integração da variável ambiental nas organizações } \\
\text { industriais: a integração pontual e a integração matricial }\end{array}$ & Teórico \\
\hline Giannetti, Almeida e & Contextualiza o conceito de eco-tecnologia empregando uma proposta de & Teórico- \\
Bonilla (2003) & aplicação para setores empresariais do Sul do Brasil & Empírico \\
\hline
\end{tabular}

\section{Tabela 5: Contribuição e Categorização Metodológica das Pesquisas Publicadas na RAC entre 1996 e 2005}

\begin{tabular}{lll}
\hline \multicolumn{1}{c}{ Pesquisa } & \multicolumn{1}{c}{ Contribuição para o campo de investigação } & \multicolumn{1}{c}{$\begin{array}{c}\text { Perfil } \\
\text { metodológico }\end{array}$} \\
\hline $\begin{array}{l}\text { Viegas e Fracasso } \\
(1998)\end{array}$ & $\begin{array}{l}\text { Analisa a relação entre capacidade tecnológica e gestão de resíduos, } \\
\text { concluindo que o incremento da capacidade tecnológica condiciona, mas não } \\
\text { determina, o bom desempenho ambiental }\end{array}$ & Teórico-Empírico \\
\hline $\begin{array}{l}\text { Lemos e Nascimento } \\
(1999)\end{array}$ & $\begin{array}{l}\text { Indica que a adoção da Produção Mais Limpa facilita o surgimento de } \\
\text { inovações e fortalece a capacidade de competição das empresas }\end{array}$ & Teórico-Empírico \\
\hline Andrade (2002) & $\begin{array}{l}\text { Investiga as interações empresa-stakeholders durante o processo de } \\
\text { formulação de estratégias ambientais }\end{array}$ & Teórico-Empírico \\
\hline $\begin{array}{l}\text { Rohrich e Cunha } \\
(2004)\end{array}$ & $\begin{array}{l}\text { Propõe uma taxonomia para se compreender a evolução da gestão ambiental } \\
\text { em empresas brasileiras }\end{array}$ & Teórico-Empírico \\
\hline
\end{tabular}

Para se verificar a demografia de autoria, adotou-se o critério de proporcionalidade utilizado por Tonelli et al. (2003), no qual se atribui valor 1 para 
o autor que publicou sozinho; 0,5 para cada um dos autores, quando a pesquisa foi realizada por uma dupla de pesquisadores; e assim por diante, considerando-se a afiliação declarada na época da publicação.

\section{Tabela 6: Contribuição e Categorização Metodológica das Pesquisas Publicadas na RAUSP entre 1996 e 2005}

\begin{tabular}{llc}
\hline \multicolumn{1}{c}{ Pesquisa } & \multicolumn{1}{c}{ Contribuição para o campo de investigação } & \multicolumn{1}{c}{$\begin{array}{c}\text { Perfil } \\
\text { metodológico }\end{array}$} \\
\hline $\begin{array}{l}\text { Miranda, Samudio e } \\
\text { Dourado (1997) }\end{array}$ & $\begin{array}{l}\text { Avalia a relação entre a evolução do paradigma da gestão ambiental e a } \\
\text { estratégia de operações da empresa }\end{array}$ & Teórico \\
\hline Motta e Rossi (2003) & $\begin{array}{l}\text { Verifica a fraca influência da variável ambiental na decisão de compra de } \\
\text { consumidores de bens de conveniência }\end{array}$ & Teórico-Empírico \\
\hline Claro e Claro (2004) & $\begin{array}{l}\text { Desenvolve indicadores para o monitoramento da sustentabilidade da } \\
\text { produção do café orgânico }\end{array}$ & Teórico-Empírico \\
\hline $\begin{array}{l}\text { Polizelli, Petroni e } \\
\text { Kruglianskas (2005) }\end{array}$ & $\begin{array}{l}\text { Combina a taxonomia dos paradigmas de gestão ambiental com dados } \\
\text { provenientes de cinco empresas líderes do setor de telecomunicações no } \\
\text { Brasil }\end{array}$ & Teórico-Empírico \\
\hline
\end{tabular}

\section{Tabela 7: Contribuição e Categorização Metodológica das Pesquisas Publicadas na RAP entre 1996 e 2005}

\begin{tabular}{|c|c|c|}
\hline Pesquisa & Contribuição para o campo de investigação & $\begin{array}{c}\text { Perfil } \\
\text { metodológico }\end{array}$ \\
\hline Barbieri (1996) & $\begin{array}{l}\text { Discorre sobre o estudo prévio de impactos ambientais apontando as } \\
\text { implicações para as empresas }\end{array}$ & Teórico \\
\hline Barbieri (1997) & $\begin{array}{l}\text { Apresenta uma abordagem conceitual acerca da relação entre políticas } \\
\text { públicas e as mudanças na tecnologia ambiental de empresas manufatureiras }\end{array}$ & Teórico \\
\hline Menezes (1997) & $\begin{array}{l}\text { Analisa as condições que determinam a emergência de políticas ambientais } \\
\text { urbanas no Brasil, com conseqüências para as unidades produtivas }\end{array}$ & Teórico \\
\hline $\begin{array}{l}\text { Guimarães, MacDowell } \\
\text { e Demarojovic (1997) }\end{array}$ & $\begin{array}{l}\text { Analisa os aspectos gerenciais dos processos de fiscalização do meio } \\
\text { ambiente no Estado de São Paulo }\end{array}$ & $\begin{array}{l}\text { Teórico- } \\
\text { Empírico }\end{array}$ \\
\hline Dias e Sanches (1999) & $\begin{array}{l}\text { Postula o fortalecimento dos procedimentos para a avaliação ambiental de } \\
\text { projetos por meio de maior controle público à luz do caso de uma pedreira }\end{array}$ & $\begin{array}{l}\text { Teórico- } \\
\text { Empírico }\end{array}$ \\
\hline Jacobi $(2000)$ & $\begin{array}{l}\text { Investiga o papel das organizações não-governamentais no processo de } \\
\text { articulação de redes ambientalistas }\end{array}$ & Teórico \\
\hline Marshall (2001) & $\begin{array}{l}\text { Recomenda existência de relação entre adoção de normas da ISO } 14000 \text { por } \\
\text { uma empresa e aumento da consciência ambiental de seus funcionários e } \\
\text { respectivas famílias }\end{array}$ & $\begin{array}{l}\text { Teórico- } \\
\text { Empírico }\end{array}$ \\
\hline Faria e Guedes (2002) & $\begin{array}{l}\text { Ressalta os desafios da pesquisa intercultural e interdisciplinar em gestão } \\
\text { ambiental empresarial }\end{array}$ & $\begin{array}{l}\text { Teórico- } \\
\text { Empírico }\end{array}$ \\
\hline Cunha (2003) & $\begin{array}{l}\text { Indica que o enfrentamento dos riscos de acidentes ambientais depende do } \\
\text { engajamento das empresas }\end{array}$ & $\begin{array}{l}\text { Teórico- } \\
\text { Empírico }\end{array}$ \\
\hline Andion (2003) & $\begin{array}{l}\text { Evidencia a importância das redes organizacionais na promoção do } \\
\text { desenvolvimento local sustentável }\end{array}$ & Teórico \\
\hline Barbieri (2004) & $\begin{array}{l}\text { Apresenta a evolução da educação ambiental no mundo e no Brasil, } \\
\text { discorrendo sobre potencialidades, desafios e consequiências de sua } \\
\text { incorporação nos cursos de administração }\end{array}$ & Teórico \\
\hline $\begin{array}{l}\text { R. A. Sanches e Villas- } \\
\text { Boas (2005) }\end{array}$ & $\begin{array}{l}\text { Mostra o papel do Instituto Socioambiental (ISA) na articulação de diversos } \\
\text { inter-locutores regionais, como grandes empresas de agronegócio, no } \\
\text { planejamento ambiental regional }\end{array}$ & $\begin{array}{l}\text { Teórico- } \\
\text { Empírico }\end{array}$ \\
\hline
\end{tabular}

O autor com maior pontuação no sistema de proporcionalidade aqui adotado é José Carlos Barbieri (FGV-EAESP), com 3,5 pontos, seguido por Luis Felipe Machado do Nascimento (UFRGS) e por Carmem Silva Sanches (FGV-EAESP), empatados com 2 pontos, à frente de José Célio Andrade (UFBA), com 1,7 
pontos. Esses quatro autores estão envolvidos na autoria exclusiva ou co-autoria de aproximadamente $32 \%$ da produção acadêmica observada. Considerando-se a tendência de valorização da produção científica em co-autoria, observada, por exemplo, por meio da priorização de projetos temáticos interinstitucionais pelas agências de fomento, dos autores com maior produção científica em gestão ambiental empresarial acima citados, aquele que mais interagiu com os demais pesquisadores foi José Cecílio de Andrade, seguido por Luiz Felipe Machado do Nascimento, Carmem Silva Sanches e José Carlos Barbieri, nesta ordem.

A análise da origem institucional da produção acadêmica em gestão ambiental empresarial (1996-2005) revela que, conforme o critério de proporcionalidade aqui adotado, a EAESP/FGV é a instituição com maior número de publicações no período, pois foi responsável por seis trabalhos. Ela é seguida pela USP, que obteve 5,5 pontos oriundos dos mais diversos cursos e centros de pesquisa, como o PROCAM e a FEA/USP. A UFRGS atingiu pontuação 5, seguida pela UFBA $(3,75)$ e pela UFSC $(2,33)$.

\section{Tabela 8: Contribuição e Categorização Metodológica das Pesquisas Publicadas na REAd entre 1996 e 2005}

\begin{tabular}{|c|c|c|}
\hline Pesquisa & Contribuição para o campo de investigação & $\begin{array}{c}\text { Perfil } \\
\text { metodológico }\end{array}$ \\
\hline Pedrozo e Silva (2000) & $\begin{array}{l}\text { Indica as contribuições do pensamento sistêmico para o desenvolvimento } \\
\text { sustentável, com implicações para as empresas }\end{array}$ & Teórico \\
\hline Nascimento (2001) & $\begin{array}{l}\text { Identifica as prioridades e ações desenvolvidas em três empresas para } \\
\text { melhorar a sua qualidade ambiental }\end{array}$ & Teórico-Empírico \\
\hline $\begin{array}{l}\text { Abreu, Figueiredo e } \\
\text { Varvakis (2002) }\end{array}$ & $\begin{array}{l}\text { Concepção e avaliação de um modelo de avaliação estratégica estrutura- } \\
\text { conduta da performance ambiental }\end{array}$ & Teórico-Empírico \\
\hline $\begin{array}{l}\text { Marinho, Andrade, } \\
\text { Cardozo e Salatiel (2002) }\end{array}$ & $\begin{array}{l}\text { Apresenta uma proposta para a análise de relatórios socioambientais } \\
\text { corporativos }\end{array}$ & Teórico-Empírico \\
\hline Orsato (2002) & $\begin{array}{l}\text { Propõe um modelo para a identificação de potencialidades para a } \\
\text { realização de investimentos ambientais }\end{array}$ & Teórico \\
\hline Campos e Selig (2002) & $\begin{array}{l}\text { Apresenta um sistema de gestão ambiental que utiliza o Balanced Score } \\
\text { Card como instrumento de integração da dimensão ambiental à estratégia } \\
\text { empresarial }\end{array}$ & Teórico-Empírico \\
\hline Venzke (2002) & $\begin{array}{l}\text { Explora que os conceitos do ecodesign não são plenamente adotados por } \\
\text { empresas do setor moveleiro }\end{array}$ & Teórico-Empírico \\
\hline $\begin{array}{l}\text { Kiperstok, Costa, } \\
\text { Andrade, Agra e } \\
\text { Figueroa (2002) }\end{array}$ & $\begin{array}{l}\text { Aborda teoricamente aspectos sobre inovações ambientais, discorrendo } \\
\text { acerca da influência da relação ambiental sobre o processo inovativo }\end{array}$ & Teórico \\
\hline Oliveira (2002) & $\begin{array}{l}\text { Analisa como a Aracruz Celulose desenvolveu sua estratégia de marketing } \\
\text { e empreendeu melhorias ambientais }\end{array}$ & Teórico-Empírico \\
\hline R. S. Souza (2002) & $\begin{array}{l}\text { Estuda os fatores que condicionam os diversos tipos de estratégias } \\
\text { ambientais nas empresas }\end{array}$ & Teórico \\
\hline $\begin{array}{l}\text { Andrade, Góes, Vargens } \\
\text { e Franco (2003) }\end{array}$ & $\begin{array}{l}\text { Objetiva criar uma grade analítica para estruturar as relações de conflito } \\
\text { existentes na área de influência do complexo turístico-hoteleiro Costa do } \\
\text { Sauípe }\end{array}$ & Teórico-Empírico \\
\hline Orsato e Leung (2003) & $\begin{array}{l}\text { Investiga as ações ambientais de uma empresa em matéria de } \\
\text { investimentos em alternativas energéticas e adequação ambiental dos } \\
\text { processos produtivos }\end{array}$ & Teórico-Empírico \\
\hline $\begin{array}{l}\text { Campos e Alberton } \\
\text { (2004) }\end{array}$ & $\begin{array}{l}\text { Avaliação da adoção de sistemas de gestão ambiental tendo em vista as } \\
\text { especificidades das pequenas empresas }\end{array}$ & Teórico-Empírico \\
\hline $\begin{array}{l}\text { Cajazeira e Barbieri } \\
(2005)\end{array}$ & $\begin{array}{l}\text { Mostra as principais alterações ocorridas na norma ISO } 14001 \text { e as } \\
\text { principais fontes de influência }\end{array}$ & Teórico \\
\hline $\begin{array}{l}\text { Nascimento e Flores } \\
(2005)\end{array}$ & $\begin{array}{l}\text { Evidencia que os estudantes universitários são receptivos aos produtos que } \\
\text { utilizam materiais reciclados em sua composição }\end{array}$ & Teórico-Empírico \\
\hline
\end{tabular}


Essas cinco instituições (EAESP/FGV, USP, UFRGS, UFBA e UFSC) foram responsáveis por aproximadamente $60 \%$ da produção acadêmica em gestão ambiental empresarial no período de 1996-2005, o que demonstra alto grau de concentração da produção intelectual em um grupo restrito de instituições.

As pesquisas aqui analisadas, teóricas ou teórico-empíricas, tiveram como inspiração 971 referências bibliográficas, das quais 51\% são internacionais. Das referências internacionais mais utilizadas, destacam-se Hunt e Auster (1990) e Porter e Linde (1995). Em termos médios, cabe indicar que cada artigo teve, aproximadamente 25 referências, sendo 13 delas internacionais.

Constata-se que, na produção acadêmica em análise, predominam trabalhos com perfil metodológico teórico-empírico, categoria em que se enquadram $61 \%$ das pesquisas. Essa característica das pesquisas tem na RAC seu caso emblemático, porque $100 \%$ dos artigos lá publicados confrontam teoria e dados empíricos (Figura 1). Não foi identificado trabalho que pudesse ser categorizado apenas como empírico. Nas pesquisas teórico-empíricas, o estudo de caso (Yin, 2004) desponta como a estratégia de investigação mais utilizada, dentro de abordagens qualitativas.

\section{Figura 1: Perfil Metodológico da Produção Acadêmica em Gestão Ambiental Empresarial entre 1996 e 2005}

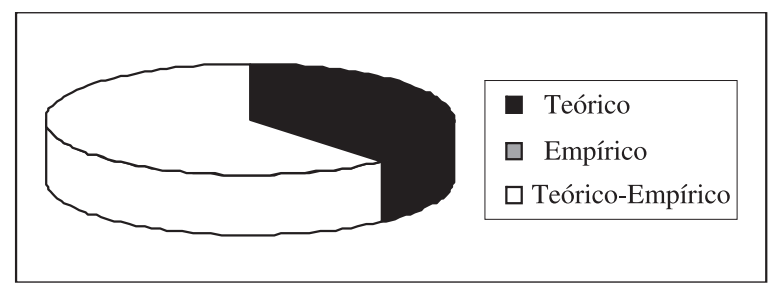

O conteúdo dos artigos que são o foco desta pesquisa (Tabela 2) pode ser analisado com base na abrangência de cada estudo, dentro de um quadro analítico proposto anteriormente por Angell e Klassen (1999). A Tabela 9 apresenta a classificação dos artigos aqui analisados. Os trabalhos que se encontram posicionados nas fronteiras entre as áreas apresentam diferentes níveis de abrangência. Por exemplo, o trabalho de Corazza (2003) empreende uma análise da gestão ambiental no contexto empresarial, com foco na integração da dimensão ambiental em áreas funcionais da empresa, o que justifica o posicionamento intermediário da pesquisa entre as abrangências funcional e empresarial. 


\section{Tabela 9: Classificação das Pesquisas por Nível de Abrangência Analítica}

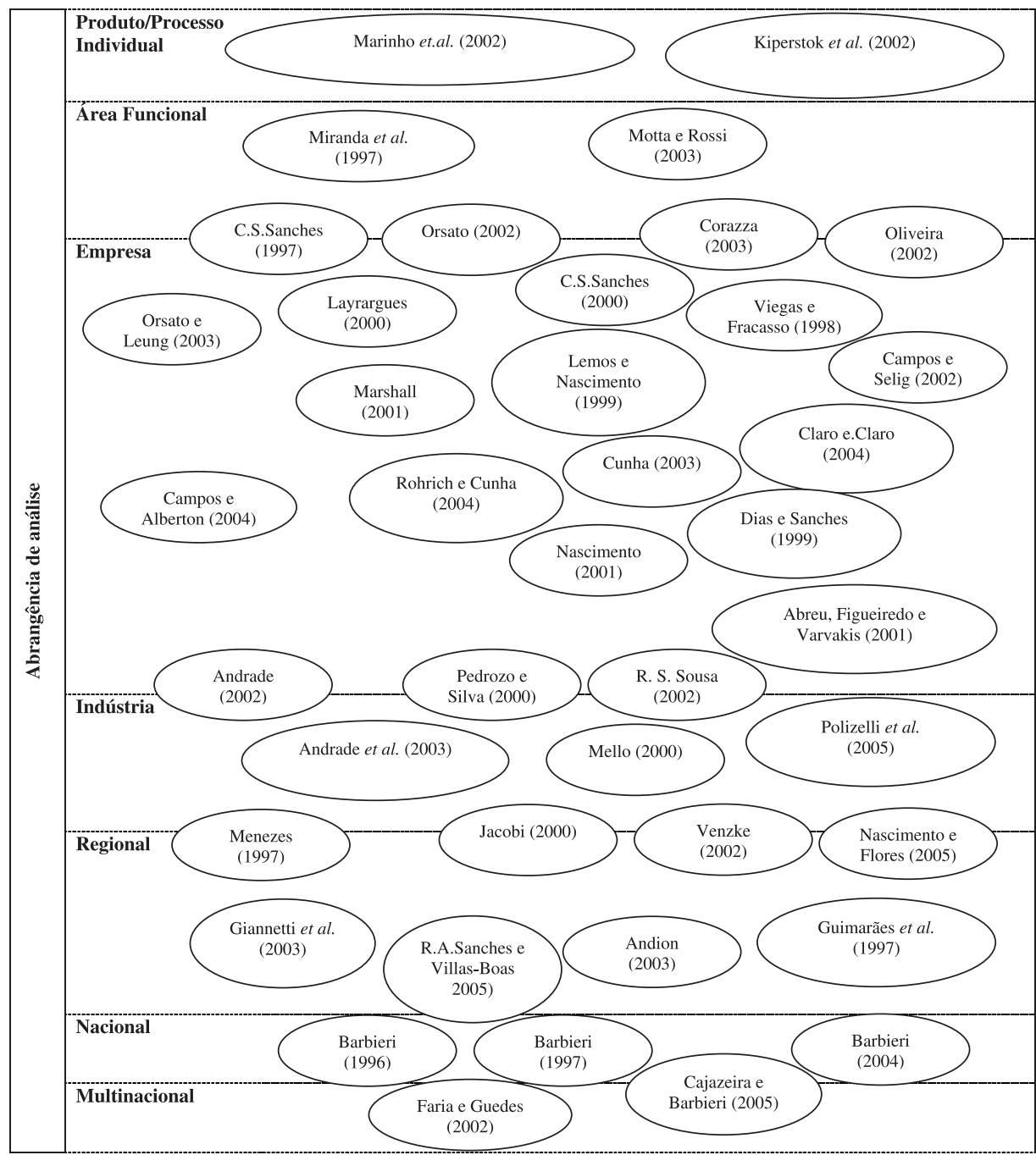

Essa classificação permite uma visualização de proposições de pesquisas $(\mathrm{P})$ em cada nível de abrangência, que podem ser úteis para futuros estudos na área de gestão ambiental empresarial, conforme o Tabela 10. Tais proposições são oriundas dos trabalhos ora analisados e demandam maior nível de reflexão a ser desenvolvido em pesquisas vindouras. 


\section{Tabela 10: Proposições de Pesquisas Futuras em Gestão Ambiental Empresarial}

\begin{tabular}{|c|c|}
\hline Abrangência de análise & Proposições de Pesquisa \\
\hline $\begin{array}{l}\text { Produto/Processo } \\
\text { Individual (P1) }\end{array}$ & $\begin{array}{l}\text { P1A: Como a questão ambiental está sendo inserida no desenvolvimento de produtos } \\
\text { ambientalmente adequados? } \\
\text { P1B: Como as organizações estão desenvolvendo competências para melhorar a } \\
\text { performance ambiental de produtos e processos? } \\
\text { P1C: As organizações estão mapeando os diversos stakeholders durante o processo } \\
\text { de desenvolvimento de produtos/processos ambientalmente adequados? } \\
\text { P1D: Como ocorre o processo de transferência de tecnologias mais limpas das } \\
\text { universidades/centros de pesquisa para as empresas? }\end{array}$ \\
\hline Área Funcional (P2) & $\begin{array}{l}\text { P2A: Como as áreas funcionais contribuem individualmente para a gestão ambiental } \\
\text { empresarial? } \\
\text { P2B: Áreas funcionais mais evoluídas favorecem a evolução da gestão ambiental na } \\
\text { empresa? }\end{array}$ \\
\hline Empresa (P3) & $\begin{array}{l}\text { P3A: A dimensão ambiental está presente na estratégia corporativa? } \\
\text { P3B: Como as diversas áreas da organização se integram para a tomada de decisão } \\
\text { em gestão ambiental? } \\
\text { P3C: Quais são os fatores críticos de sucesso na implementação e manutenção de } \\
\text { sistemas de gestão ambiental? }\end{array}$ \\
\hline Indústria (P4) & $\begin{array}{l}\text { P4A: A importância da dimensão ambiental para o sucesso empresarial varia entre } \\
\text { diversas indústrias/ramos de atuação? } \\
\text { P4B: Quando uma empresa localizada em determinada indústria começa a se } \\
\text { preocupar com a dimensão ambiental as demais empresas da mesma indústria } \\
\text { sensibilizam-se para a causa? } \\
\text { P4C: Quais são os benefícios de um benchmarking em gestão ambiental de uma dada } \\
\text { indústria para as empresas componentes? }\end{array}$ \\
\hline Região (P5) & $\begin{array}{l}\text { P5A: As peculiaridades das diversas regiões dentro de um país condicionam o } \\
\text { desempenho em gestão ambiental de empresas situadas em diferentes pontos do } \\
\text { território? } \\
\text { P5B: Há transferência de tecnologias mais limpas entre as regiões? }\end{array}$ \\
\hline Nacional (P6) & $\begin{array}{l}\text { P6A: Quais são os efeitos dos incentivos governamentais para a produção de } \\
\text { tecnologias mais limpas no contexto empresarial? } \\
\text { P6B: A política nacional de educação ambiental está surtindo efeito sobre a } \\
\text { consciência ambiental dos gestores? }\end{array}$ \\
\hline Multinacional (P7) & $\begin{array}{l}\text { P7A: Há transferência de tecnologias mais limpas entre as nações? } \\
\text { P7B: Quais são os efeitos dos programas de instituições multilaterais para a melhoria } \\
\text { da gestão ambiental nas organizações? } \\
\text { P7C: Como a unificação das nações em blocos pondera a dimensão ambiental no } \\
\text { contexto empresarial? } \\
\text { P7D: Como empresas em processo de internacionalização alinham sua dinâmica de } \\
\text { gestão ambiental às especificidades do país de destino? }\end{array}$ \\
\hline
\end{tabular}

\section{Considerações Finais}

O presente trabalho lançou luzes sobre a produção acadêmica em gestão ambiental empresarial registrada durante o período de 1996-2005. Foram da ordem de 41 os trabalhos publicados dentre os 1.785 registrados nos seis periódicos analisados. Isso significa que a produção científica dessa área de pesquisa corresponde a apenas $2,30 \%$ do total da área de administração. Assim, a despeito da área de gestão ambiental empresarial ser uma das mais concorridas no âmbito dos eventos acadêmicos em administração, ela ainda encontra pouco eco nos 
periódicos de grande prestígio. Ressalte-se que o quadro só não se mostrou mais crítico pelo lançamento de uma edição especial da REAd sobre o tema.

Não apenas a baixa quantidade de trabalhos publicados, mas a falta de diversidade de autoria também se revela preocupante, porquanto, além de haver concentração da massa crítica em gestão ambiental em determinados centros de ensino e pesquisa, grande parte da produção é relativa a um restrito número de pesquisadores. Apenas cinco instituições de ensino e pesquisa são responsáveis por quase $60 \%$ da produção observada, que se mostra, no todo ou em parte, atrelada a quatro pesquisadores que, tomados em conjunto, correspondem a $32 \%$ das pesquisas em gestão ambiental empresarial dos periódicos examinados.

Quanto à análise do perfil metodológico das pesquisas avaliadas, fica evidente a predominância de estudos teórico-empíricos qualitativos, que se valem de estudo de casos. Essa tendência parece desconectada do padrão metodológico das pesquisas internacionais na área. De fato, nos principais veículos acadêmicos internacionais sobre gestão ambiental, tal como o Journal of Cleaner Production, há predominância de pesquisas teórico-empíricas quantitativas.

Aproximadamente $50 \%$ das referências bibliográficas que serviram de inspiração teórica para a produção acadêmica em gestão ambiental empresarial são internacionais; as mais citadas são Hunt e Auster (1990) e Porter e Linde (1995). Esse uso recorrente de pesquisas estrangeiras na produção acadêmica analisada pode ser explicado, pelo menos parcialmente, pelo número restrito de artigos publicados nas principais revistas nacionais de administração.

O levantamento aqui realizado objetiva, outrossim, indicar potenciais linhas de estudo para pesquisas em gestão ambiental empresarial. Com base nas sugestões temáticas ora propostas, dirigentes empresariais podem engajar-se no financiamento e acompanhamento de pesquisas de temas específicos de interesse para o desempenho organizacional em gestão ambiental, dentro de um contexto de incremento entre a produção acadêmica em gestão ambiental empresarial e as demandas do âmbito empresarial.

\section{Comparação com Outros Trabalhos e Implicações para o Campo de Estudo}

Os resultados deste estudo assemelham-se, em algumas partes, aos obtidos em outros balanços da literatura em distintas áreas da produção acadêmica em administração. A restrição da produção acadêmica foi apontada por Tonelli et al. (2003), em estudo com foco nas publicações em gestão de recursos humanos, cuja conclusão mostrou que mais de $65 \%$ da produção acadêmica é oriunda de 
apenas sete programas de pós-graduação. Tais constatações assemelham-se àquelas inferidas neste estudo: cinco instituições são responsáveis por quase $60 \%$ da produção acadêmica em gestão ambiental empresarial.

Quanto ao perfil metodológico, os resultados constatados por Meirelles e Hoppen (2005) indicam redução na proporção de ensaios teóricos, o que se assemelha à predominância de estudos teórico-empíricos qualitativos produzidos na área de gestão ambiental empresarial. O estudo de casos revelou-se como estratégia de pesquisa recorrente nos trabalhos aqui analisados, alinhando-se aos resultados obtidos por Gosling e Gonçalves (2004), os quais observaram sua adoção em aproximadamente 58\% das pesquisas em estratégia analisadas pelos autores.

Leal et al. (2003) constataram que a produção acadêmica em finanças se concentra em poucos autores nacionais, como ocorre na área de gestão ambiental empresarial, aqui analisada.

A utilização de referências estrangeiras na produção em administração foi um dos objetos da pesquisa de Vieira (2003) sobre marketing. O autor conclui que, quando o pesquisador brasileiro da área investigada utiliza periódicos, ele o faz privilegiando os internacionais, conclusão similar à observada neste estudo.

Dessa forma, é possível propor hipóteses $(\mathrm{H})$ de pesquisa a serem investigadas futuramente, para contemplarem áreas específicas do conhecimento em administração ou para o desenvolvimento de teste comparado dessas hipóteses em diversas áreas.

- H1: A produção acadêmica em administração é oriunda de um número restrito de centros de ensino e pesquisa.

. H2: Há predominância de estudos teórico-empíricos sobre os trabalhos de natureza teórica, com preferência pela realização de estudo de casos.

. H3: A produção acadêmica em determinada área do campo da administração é determinada pela produção de um grupo específico de pesquisadores.

. H4: A produção científica internacional influencia fortemente a produção acadêmica em administração no Brasil.

Muitos estudos analisaram a produção científica em administração registrada nos anais de eventos, principalmente do ENANPAD. Como comparativamente a este estudo os anais do ENANPAD e do ENGEMA não se constituíram em objeto analítico, propõem-se as hipóteses H5 e H6. 
. H5: Haverá um incremento quantitativo na produção científica em gestão ambiental dos periódicos considerados nesta pesquisa empresarial, oriunda dos trabalhos apresentados no ENANPAD.

. H6: O fortalecimento de fóruns de debate específicos em gestão ambiental empresarial, tal como o ENGEMA, contribuirá para o aumento do número de artigos registrados nos periódicos em administração.

O teste das hipóteses $\mathrm{H} 5$ e H6 pode conduzir a um novo campo de pesquisa no contexto da temática em gestão ambiental empresarial, qual seja, o da investigação dos fatores promotores e inibidores do transbordamento da produção científica apresentada em congressos para as revistas de maior prestígio. Alguns fatores inibidores podem ser assinalados, tais como o maior rigor do trabalho científico exigido para a publicação nas revistas mais conceituadas da área de administração (Tonelli et al., 2003) e a possível morosidade do processo de publicação em periódicos. Além desses aspectos, deve-se considerar que a publicação em gestão ambiental empresarial, por sua natureza multidisciplinar, pode ser registrada em periódicos de outras áreas, como os da engenharia de produção, engenharia ambiental, turismo, economia etc. Por outro lado, podem estar registradas em periódicos de menor prestígio da área de administração, não contemplados neste trabalho. Essa investigação pode se revelar pertinente também para as demais áreas de conhecimento em administração.

\section{Artigo recebido em 17.08.2006. Aprovado em 04.12.2006.}

\section{Agradecimento}

Agradecemos à FAPESP pelos recursos concedidos.

\section{RefERÊnCIAS BibliográficAs}

Abreu, M. C. S.,

Figueiredo, H. S., Jr., \&

Varvakis, G. (2002).

Modelo de avaliação da estratégia ambiental: os perfis de conduta estratégica. Revista Eletrônica de Administração, 8(6), 1-25. Recuperado em 22 janeiro, 2006, de http://read.adm.ufrgs.br/edicoes/ anteriores.php

Andion, C. (2003).

Análise de redes e desenvolvimento local sustentável. Revista de Administração Pública, 37(5), 1033 1054. 
Andrade, J. C. S. (2002).

Formação de estratégias socioambientais corporativas: os jogos Aracruz Celulose-Partes Interessadas. Revista de Administração Contemporânea, 6(2), 75-97.

Andrade, J. C. S.,

Góes, M. F. B.,

Vargens, E. C., \&

Franco, M. T. K. (2003).

Conflitos sócio-ambientais na área de influência do complexo Costa do Sauípe: proposta de uma grade analítica. Revista Eletrônica de Administração, 9(2), 1-18. Recuperado em 22 janeiro, 2006, de http://read.adm.ufrgs.br/edicoes/ anteriores.php

Angell, L. C., \&

Klassen, R. D. (1999).

Integrating environmental issues into the mainstream: an agenda for research in operations management. Journal of Operations Management, 17(5), 575-598.

Arkader, R. (2003).

A pesquisa científica em gerência de operações no Brasil. Revista de Administração de Empresas, 43(1), 70-80.

Barbieri, J. C. (1996).

Estudo prévio de impacto ambiental no estado de São Paulo. Revista de Administração Pública, 30(2), 152166.

Barbieri, J.C. (1997).

Políticas públicas indutoras de inovações tecnológicas ambiental- mente saudáveis nas empresas. Revista de Administração Pública, 31(2), 135-152.

Barbieri, J. C. (2004).

Educação ambiental e a gestão ambiental em cursos de graduação em administração: objetivos, desafios e propostas. Revista de Administração Pública, 38(6), 919-946.

Botelho, D., \&

Macera, A. P. (2001, setembro).

Análise metateórica de teses e dissertações da área de marketing apresentadas na EAESP-FGV (19741999). Anais do Encontro Nacional da Associação Nacional de PósGraduação e Pesquisa em Administração, Campinas, SP, Brasil, 25.

Buchoolz, R. A. (1998).

Principles of environmental management: the greening of business. Londres: Prentice Hall.

Cajazeira, J. E. R., \&

Barbieri, J. C. (2005).

A nova versão da norma ISO 14001: as influências presentes no primeiro ciclo revisional e as mudanças efetuadas. Revista Eletrônica de Administração, 11(6), 1-26. Recuperado em 22 janeiro, 2006, de http://read.adm.ufrgs.br/edicoes/ anteriores.php

Caldas, M. P., \&

Tinoco, T. (2004).

Pesquisa em gestão de recursos humanos nos anos 1990: um estudo bibliométrico. Revista de Administração de Empresas, 44(3), 100-114. 
Caldas, M. P.,

Tinoco, T., \&

Chu, R. (2003, setembro).

Análise bibliométrica dos artigos de RH publicados no ENANPAD na década de 1999: um mapeamento a partir das citações dos heróis, endogenias e jactâncias que fizeram a história recente da produção científica da área. Anais do Encontro Nacional da Associação Nacional de PósGraduação e Pesquisa em Administração, Atibaia, SP, Brasil, 27.

Campos, L. M. S., \&

Alberton, A. (2004).

Environmental management systems (EMS) in the context of small business: a study conduced in the south of Brazil. Revista Eletrônica de Administração, 10(6), 1-32. Recuperado em 22 janeiro, 2006, de http://read.adm.ufrgs.br/edicoes/ anteriores.php

Campos, L. M. S., \&

Selig, P. M. (2002).

SGADA - Sistema de gestão e avaliação do desempenho ambiental: a aplicação de um modelo SGA que utiliza o Balanced Score Card (BSC). Revista Eletrônica de Administração, 8(6), 1-23. Recuperado em 22 janeiro, 2006, de http://read.adm.ufrgs.br/edicoes/ anteriores.php

Carneiro, J. M. B.,

Magyar, A. L., \&

Granja, S. I. B. (1993).

Meio ambiente, empresário e governo: conflitos ou parcerias. Revista de Administração de Empresas, 33(3), 68-75.
Cicco, F. (1994).

ISO 14000: a nova norma de gerenciamento e certificação ambiental. Revista de Administração de Empresas, 34(5), 80-84.

Claro, P. B. O., \&

Claro, D. P. (2004).

Desenvolvimento de indicadores para monitoramento da sustentabilidade: o caso do café orgânico. Revista de Administração, 39(1), 18-29.

Corazza, R. I. (2003).

Gestão ambiental e mudanças da estrutura organizacional. $R A E$ eletrônica, 2(2), 1-23. Recuperado em 22 janeiro, 2006, de http://www.rae. com.br/eletronica/index.cfm? Fuse Action $=$ Artig o \& ID = $1392 \&$ Secao $=$ ORGANIZA\& Volume $=2 \&$ numero $=2 \& A n o=2003$

Cunha, I. (2003).

Insalubridade e conflito ambiental: risco e cidadania. Revista de Administração Pública, 37(2), 443457.

Dias, E. G. C. S., \&

Sanches, L. E. (1999).

A participação pública versus os procedimentos burocráticos no processo de avaliação de impactos ambientais de uma pedreira. Revista de Administração Pública, 33(4), 8191.

Donaire, D. (1994).

Considerações sobre a influencia da variável ambiental na empresa. Revista de Administração de Empresas, 34(2), 68-77. 
Faria, A., \&

Guedes, A. L. M. (2002).

Pesquisa intercultural e interdisciplinar em gestão internacional: investigações em marketing internacional e gestão ambiental. Revista de Administração Pública, 36(5), 747-776.

Giannetti, B. F.,

Almeida, C. M. V. B., \&

Bonilla, S. H. (2003).

Implementação de eco-tecnologias rumo à ecologia industrial. $R A E$ Eletrônica, 2(1), 1-19. Recuperado em 22 janeiro, 2006, de http://www.rae. com.br/eletronica/index.cfm? Fuse Action $=$ Artig o \& I D = $1236 \&$ Secao $=$ CINCIA $\&$ Volume $=$ $2 \&$ numero $=1 \& A$ no $=2003$

Gosling, M., \&

Goncalves, C. A. (2004).

Idéias metodológicas dos autores de estratégia dos ENANPADs: uma metaanálise. Revista Eletrônica da Administração, 10(5), 1-26. Recuperado em 22 janeiro, 2006, de http://read.adm.ufrgs.br/edicoes/ anteriores.php

Guimarães, P. C. V.,

Demajorovic, J., \&

Oliveira, R. G. (1995).

Estratégias empresariais e instrumentos econômicos de gestão ambiental. Revista de Administração de Empresas, 35(5), 72-82.

Guimarães, P. C. V.,

Macdowell, S. F., \&

Demajorovic, J. (1997).

Fiscalização do meio ambiente no estado de São Paulo. Revista de Administração Pública, 31(1), 96-111.
Hart, S. L. (1995).

A natural-resource-based view of the firm. Academy of Management, 20(4), 986-1014.

Hoppen, N. (1998).

Sistemas de informação no Brasil: uma análise dos artigos científicos dos anos 90. Revista de Administração Contemporânea, 2(3), 151-177.

Huber, J. C., \&

Wagner-Dobler, R. (2001a).

Scientific production: a statistical analysis of authors in physics, 18001900. Scientometrics, 50(3), 437-453.

Huber, J. C., \&

Wagner-Dobler, R. (2001b).

Scientific production: a statistical analysis of authors in mathematical logic. Scientometrics, 50(2), 323-337.

Hunt, C. B., \&

Auster, E. R. (1990).

Proactive

environmental management: avoiding the toxic trap. MIT Sloan Management Review, 31(2), 7-18.

Iizuka, E. S., \&

Sano, H. (2004, setembro).

O terceiro setor e a produção acadêmica: uma visita aos anais dos ENANPAD's de 1990 a 2003. Anais do Encontro Nacional da Associação Nacional de Pós-Graduação e Pesquisa em Administração, Curitiba, PR, Brasil, 28.

Jacobi, P. (2000).

Meio ambiente e redes sociais: dimensões intersetoriais e complexidade na articulação de práticas coletivas. Revista de Administração Pública, 34(6), 131-158. 
Kiperstok, A.,

Costa, D. P.,

Andrade, J. C.,

Agra, S., Filho, \&

Figueroa, E. (2002).

Inovação como requisito do desenvolvimento sustentável. Revista Eletrônica de Administração, 8(6), 120. Recuperado em 22 janeiro, 2006, de http://read.adm.ufrgs.br/edicoes/ anteriores.php

Layrargues, P. P. (2000).

Sistemas de gerenciamento ambiental, tecnologia limpa e consumidor verde: a delicada relação empresa-meio ambiente no ecocapitalismo. Revista de Administração, 40(2), 80-88.

Leal, R. P. C.,

Oliveira, J., \&

Soluri, A. F. (2003).

Perfil da pesquisa em finanças no Brasil. Revista de Administração de Empresas, 43(1), 91-104.

Lemos, A. D., \&

Nascimento, L. F. (1999).

A produção mais limpa como geradora de inovação e competitividade. Revista de Administração Contemporânea, 3(1), 23-46.

Lunardi, G. L.,

Rios, L. R., \&

Maçada, A. C. G. (2005, setembro).

Pesquisa em sistemas de informação: uma análise a partir dos artigos publicados no Enanpad e nas principais revistas nacionais de administração. Anais do Encontro Nacional da Associação Nacional de Pós-Graduação e Pesquisa em Administração, Brasília, DF, Brasil, 29.
Machado-da-Silva, C. L.,

Cunha, V. C., \&

Amboni, N. (1990).

Organizações: o estado da arte da produção acadêmica no Brasil. Anais do Encontro Nacional da Associação Nacional de Pós-Graduação e Pesquisa em Administração, Florianópolis, SC, Brasil, 14.

Maimon, D. (1994).

Eco-estratégia nas empresas brasileiras: realidade ou discurso? Revista de Administração de Empresas, 34(4), 119-130.

Maimon, D. (1996).

Passaporte verde: gestão ambiental e competitividade. Rio de Janeiro: Qualitymark.

Marinho, M. M. O.,

Andrade, J. C. S.,

Cardozo, L. F., \&

Salatiel, M. (2002).

Relatório socioambiental corporativo e produção sustentável. Revista Eletrônica de Administração, 8(6), 117. Recuperado em 22 janeiro, 2006, de http://read.adm.ufrgs.br/edicoes/ anteriores.php

Marshall, I., Jr. (2001).

Certificação ambiental em empresas industriais: o caso Bayer e os reflexos na conscientização de seus funcionários e famílias. Revista de Administração Pública, 35(3), 77-106.

Mazon, R. (1992).

Em direção a um novo paradigma de gestão ambiental - tecnologias limpas ou prevenção de poluição. Revista de Administração de Empresas, 32(2), 78-98. 
Meirelles, F. S., \&

Hoppen, N. (2005).

Sistemas de informação: a pesquisa científica brasileira entre 1990 e 2003. Revista de Administração de Empresas, 45(1), 24-35.

Mello, R. (2000).

Rumo à sustentabilidade da produção de cana-de-açúcar em São Paulo: as contas ambientais. Revista de Administração de Empresas, 40(3), 74-82.

Mendonça, O. R.,

Neto, Riccio, E. L.,

Cardoso, R. L., \&

Sakata, M. C. G. (2005).

Pesquisa científica em contabilidade entre 1990 e 2003. Revista de Administração de Empresas, 45(2), 34-45.

Menezes, C. L. (1997).

Emergência e evolução da política ambiental urbana no Brasil: do Estado Novo à Nova República. Revista de Administração Pública, 31(1), 70-95.

Miranda, N. G. M.,

Samudio, E. M. M., \&

Dourado, F. F. M. (1997).

A estratégia de operações e a variável ambiental. Revista de Administração, 32(1), 58-67.

Motta, S. L., \&

Rossi, G. B. (2003).

Influência fator ecológico na decisão de compra de bens de conveniência: um estudo exploratório na cidade de São Paulo. Revista de Administração, 38(1), 46-57.
Nahuz, M.A. R. (1995).

O sistema ISO 14000 e a certificação ambiental. Revista de Administração de Empresas, 35(6), 55-66.

Nascimento, L. F. (2001).

A qualidade ambiental em empresas do setor primário, secundário e terciário: um estudo de três casos. Revista Eletrônica de Administração, 7(3), 1-14. Recuperado em 22 janeiro, 2006, de http://read.adm. ufrgs.br/edicoes/anteriores.php

Nascimento, L. F., \&

Flores, S. S. (2005).

Aceitação de produtos que utilizam matéria-prima reciclada em sua composição. Revista Eletrônica de Administração, 11(6), 1-24. Recuperado em 22 janeiro, 2006, de http:// read.adm.ufrgs.br/edicoes/ anteriores.php

Neder, R. T. (1992).

Há política ambiental para a indústria brasileira? Revista de Administração de Empresas, 32(2), 6-13.

Oliveira, J.A. P. (2002).

Integrando ação e comunicação para uma estratégia de marketing ambiental: o caso Aracruz Celulose. Revista Eletrônica de Administração, 8(6), 1-23. Recuperado em 22 janeiro, 2006, de http://read.adm. ufrgs.br/edicoes/anteriores.php

Orsato, R. (2002).

Posicionamento ambiental estratégico: identificando quando vale a pena investir no verde. Revista Eletrônica de Administração, 8(6), 129. Recuperado em 22 janeiro, 2006, de http://read.adm.ufrgs.br/edicoes/ anteriores.php 
Orsato, R., \&

Leung, P. (2003).

The pragmatic challenge of sustainable development: lessons from Shell Canadá. Revista Eletrônica de Administração, 9(6), 1-20. Recuperado em 22 janeiro, 2006, de http://read.adm.ufrgs.br/edicoes/ anteriores.php

Paiva, F. G., Jr., \&

Cordeiro, A. T. (2002, setembro).

Empreendedorismo e espírito empreendedor: uma análise da evolução dos estudos na produção acadêmica brasileira. Anais do Encontro Nacional da Associação Nacional de Pós-Graduação e Pesquisa em Administração, Salvador, BA, Brasil, 26.

Pedrozo, E. A., \&

Silva, T. N. (2000).

O desenvolvimento sustentável e a abordagem sistêmica. Revista Eletrônica de Administração, 6(6), 1-36. Recuperado em 22 janeiro, 2006, de http://read.adm.ufrgs.br/edicoes/ anteriores.php

Polizelli, D. L.,

Petroni, L. M., \&

Kruglianskas, I. (2005).

Gestão ambiental nas empresas líderes do setor de telecomunicações no Brasil. Revista de Administração, 40(4), 309-320.

Porter, M. E., \&

Linde, C. V. D. (1995).

Green and competitive: ending the stalemate. Harvard Business Review, 73(5), 120-134.
Roesch, S.,

Antunes, E., \&

Silva, L. V. (1997, setembro).

Tendências da pesquisa em recursos humanos e organizações: uma análise das dissertações de mestrado. Anais do Encontro Nacional da Associação Nacional de PósGraduação e Pesquisa em Administração, Rio das Pedras, RJ, Brasil, 21.

Rohrich, S. S., \&

Cunha, J. C. (2004).

A proposição de uma taxonomia para a análise da gestão ambiental no Brasil. Revista de Administração Contemporânea, 8(4), 81-97.

Sanches, C. S. (1997).

Mecanismos de interiorização dos custos ambientais na indústria: rumo a mudanças de comportamento. Revista de Administração de Empresas, 37(2), 56-67.

Sanches, C. S. (2000).

Gestão ambiental proativa. Revista de Administração de Empresas, 40(1), 76-87.

Sanches, R. A., \&

Villas-Boas, A. (2005).

Planejando a gestão em um cenário socioambiental de mudanças: o caso da bacia do rio Xingu. Revista de Administração Pública, 39(2), 365 380.

Seiffert, M. E. B. (2005).

ISO 14001: sistemas de gestão ambiental. São Paulo: Atlas. 
Siqueira, M. (1988, setembro).

O tema recursos humanos nas reuniões da ANPAD: trajetórias e perspectivas. Anais do Encontro Nacional da Associação Nacional de Pós-Graduação e Pesquisa em Administração, Foz do Iguaçu, PR, Brasil, 12.

Souza, M. T. S. (1993).

Rumo à prática empresarial sustentável. Revista de Administração de Empresas, 33(4), 40-52.

Souza, R. S. (2002).

Evolução e condicionantes da gestão ambiental na empresa. Revista Eletrônica de Administração, 8(6), 122. Recuperado em 22 janeiro, 2006, de http://read.adm.ufrgs.br/edicoes/ anteriores.php

Tonelli, M. J.,

Caldas, M. P.,

Lacombe, B. M. B., \&

Tinoco, T. (2003).

Produção acadêmica em recursos humanos no Brasil: 1991-2000. Revista de Administração de Empresas, 43(1), 105-122.

Venzke, C. S. (2002).

O ecodesign no setor moveleiro do Rio Grande do Sul. Revista Eletrônica de Administração, 8(6), 1-13. Recuperado em 22 janeiro, 2006, de http://read.adm.ufrgs.br/edicoes/ anteriores.php

Viegas, C., \&

Fracasso, E. M. (1998).

Capacidade tecnológica e gestão de resíduos em empresas de calçados do Vale dos Sinos: estudo de dois casos. Revista de Administração Contemporânea, 2(2), 41-62.

Vieira, F. G. D. (2003).

Narciso sem espelho: a publicação brasileira de marketing. Revista de Administração de Empresas, 43(1), 81-90.

Yin, R. (2004).

Estudo de casos: planejamento e métodos. São Paulo: Bookman. 